\title{
Eccrine Porocarcinoma: A Case Report
}

\author{
(D) Ahmet Bahadır Göktaş¹, (D) Özben Yalçın¹, (D) Elif Moustafa² \\ 1 University of Health Sciences Turkey, Prof. Dr. Cemil Taşcıoğlu City Hospital, Clinic of Pathology, Istanbul, Turkey \\ 2 University of Health Sciences Turkey, Prof. Dr. Cemil Taşcıoğlu City Hospital, Clinic of Dermatology, istanbul, Turkey
}

\section{Abstract}

Eccrine porocarcinoma is a rare carcinoma but it is the most common malignant sweat gland tumor. It can develop de novo or from poroma ground. It is mostly seen in elderly patients and the most common locations are the lower limbs, the trunk, and the head and neck. This condition is an important differential diagnosis in several clinical entities. We present a case of eccrine porocarcinoma diagnosed clinically and histomorphologically. We also reviewed the available information on this condition from published literature.

Keywords: Eccrine porocarcinoma, head and neck tumors, cutaneous adnexal tumors

\section{INTRODUCTION}

Eccrine porocarcinoma, initially defined as epidermotropic eccrine carcinoma in 1963 by Pinkus and Mehragen (1), is a rare malignant sweat gland tumor originating from acrosyringeal cells. It is the most common malignant sweat gland tumor and constitutes $0.005-0.01 \%$ of all cutaneous tumors (2). It can develop de novo from normal sweat gland cells, as well as from malignant transformation of poroma ground. It is more common in women and in elderly patients. Clinically, eccrine porocarcinoma presents as a papule, plaque, nodule, or polyp which may have ulcerations. The most common locations are the lower extremities, the trunk, and the head and neck, but it can develop in any location (3). It is characterized histopathologically by large anastomosed epithelial islands associated with the epidermis and may extend deep. Intercellular bridges can be seen between cells while peripheral palization is not observed (4). Wide local excision is the best treatment option (5).

In this case report, we present a case of eccrine porocarcinoma developing on the malar region on both sides of an 82-year-old female patient who was previously diagnosed with high-grade carcinoma.

\section{CASE PRESENTATION}

An 82-year-old female patient had lesions on the bilateral malar regions that started 1 year ago. On physical examination, there was a $4 \mathrm{~cm}$, elevated tumoral lesion, with irregular borders, hyperemic periphery, and hemorrhagic surface on each malar region. Punch biopsy was performed due to suspicion of malignancy (Figure 1). Both lesions were excised after the biopsy result reported high-grade squamous cell carcinoma.

On macroscopic examination, the tumor from the right malar region was seen $1.5 \mathrm{~cm}$ raised from the skin, measured $3.5 \times 2.5$ $\mathrm{cm}$, and had irregular borders. The tumor from the left malar region was raised $1.7 \mathrm{~cm}$ from the skin, measured $4 \times 2.5 \mathrm{~cm}$, and also had irregular borders.

Microscopic examination revealed a tumoral formation consisting of trabeculae of different sizes that were anastomosed to each other and were continuous with the epidermis (Figure 2). Although the tumor mostly showed an expansive growth pattern, invasive areas were also seen. Tumor cells consisted of basaloid cells with prominent cytological atypia, hyperchromatic nucleus, nucleolar prominence, high mitotic activity, and prominent pleomorphism (Figure 3). Cells with 
clear cytoplasm and focal squamous cell differentiation were seen in some areas (Figure 4). Areas of ductal differentiation and

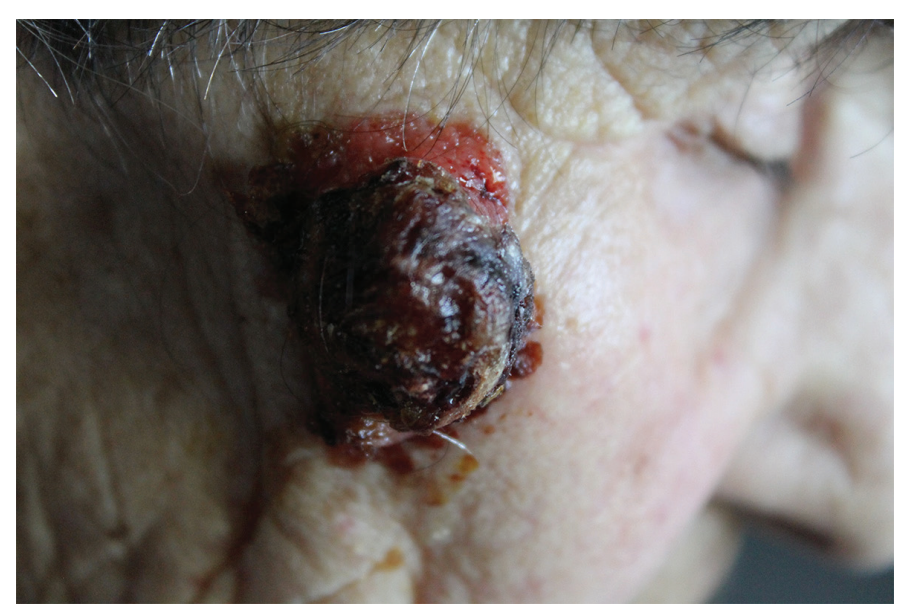

Figure 1. Tumoral lesions located in both malar regions, with irregular surface and borders, and hemorrhagic surface

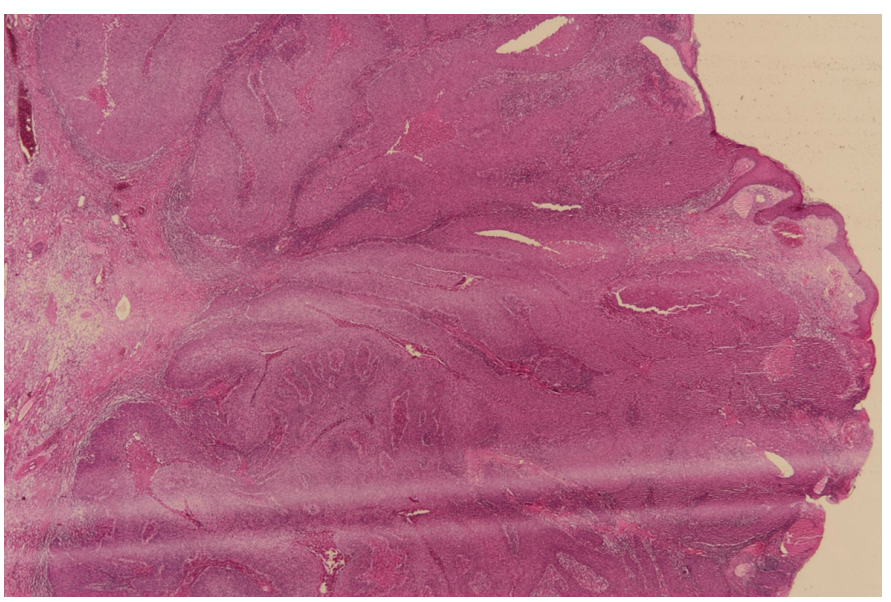

Figure 2. Tumor islands anastomosing with each other showing continuity with the epidermis (H\&Ex20)

H\&E: Hematoxylin and eosin

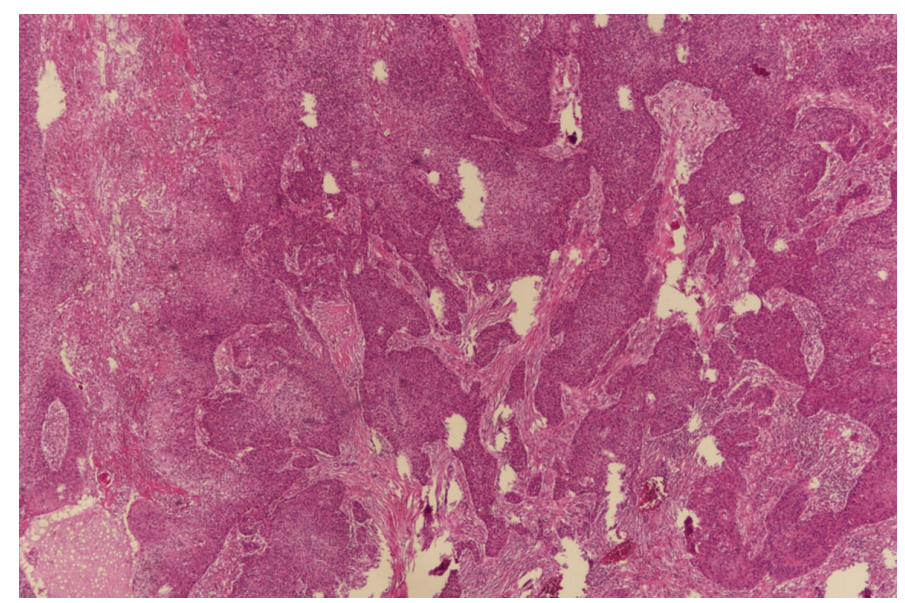

Figure 3. Tumor cells showing large tumor islands and an infiltrative growth pattern. (H\&Ex40)

H\&E: Hematoxylin and eosin rare intracytoplasmic lumen formation were detected (Figure 5). Necrosis was seen in the middle of the tumor islands. Upon histochemical study, periodic acid-Schiff (PAS) positivity was observed in clear cell areas. In neoplastic cells, the following immunohistochemical findings were observed: Diffuse positive staining with CK5-6, p63, and EMA, focal positive staining with CD117, positive staining with carcinoembryonic antigen (CEA) in ductal differentiation areas, and negative staining with BerEp4 (Figure 6). The Ki-67 proliferative index was 65-70\% (Figure 7). These histomorphological and immunohistochemical findings confirm the diagnosis of eccrine porocarcinoma for both lesions.

\section{DISCUSSION}

Eccrine porocarcinoma is a rare malignant sweat gland tumor that can develop de novo or from poroma ground. Clinically, it can be confused with seborrheic keratosis, pyogenic granuloma, verruca, or squamous cell carcinoma (6). Eccrine

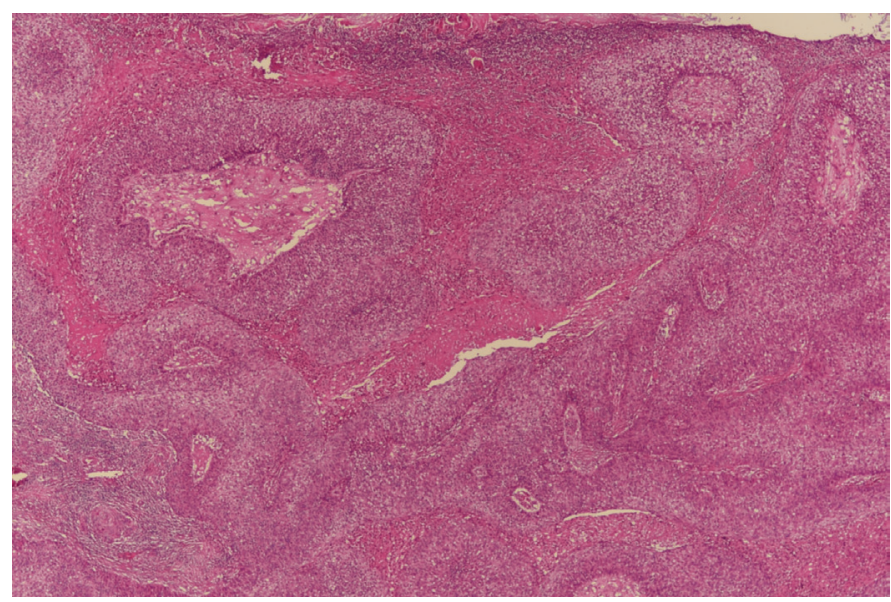

Figure 4. Note clear cell change and necrosis (H\&Ex40) H\&E: Hematoxylin and eosin

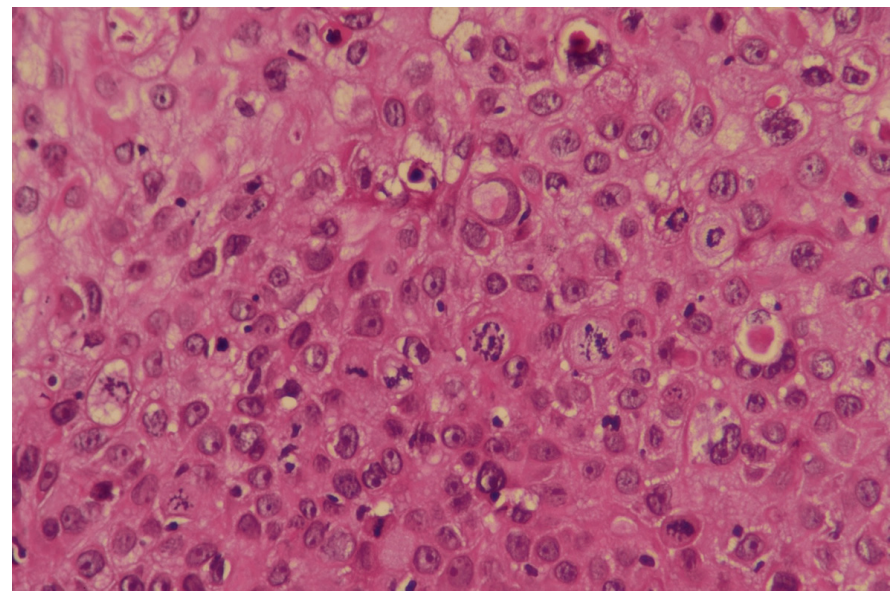

Figure 5. Tumor cells showing cytological atypia, mitosis, and pleomorphism. Note the intracytoplasmic lumen (H\&Ex400) H\&E: Hematoxylin and eosin 
porocarcinoma has a high risk of recurrence and metastasis. Mortality rate is highly correlated with the presence of metastases (7). The more common invasive form shows an infiltrative or expansive growth pattern in addition to in situ areas. Tumor cells continuing with the epidermis consist of trabeculae that anastomose with each other in an asymmetrical appearance. Cytologically, high mitotic activity, pleomorphism, nuclear atypia, and nucleolar prominence are seen. Necrosis is common. Ductal differentiation areas, intracytoplasmic lumen, focal squamous differentiation areas, and clear cell change can be seen (7-10). Rarely, sebaceous differentiation areas may accompany (11).

Immunhistochemical findings can show overexpression with P53 and negative staining with S100 and BerEP4 but these do not have a significant role in the diagnosis. Demonstrating ductal differentiation areas immunohistochemically with CEA and epithelial membrane antigen (EMA) is more helpful in diagnosis and can also be demonstrated histochemically with D-PAS $(12,13)$.

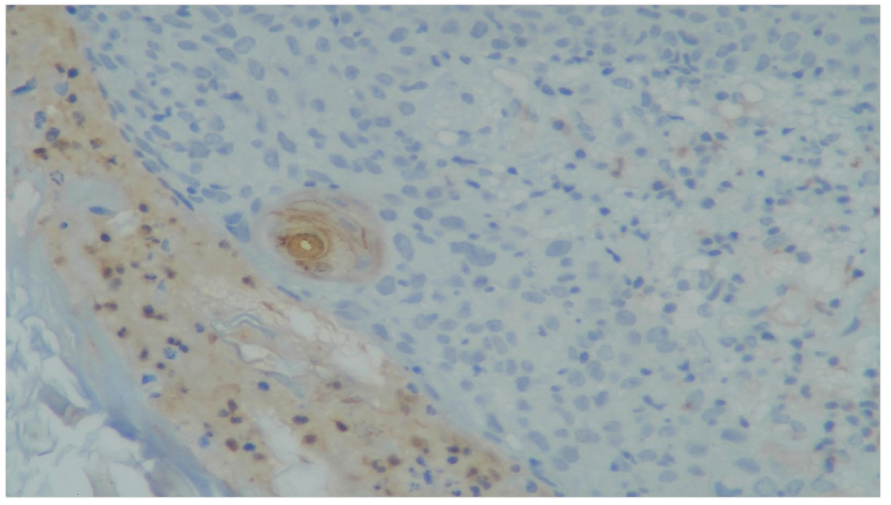

Figure 6. Positive staining with CEA in cells showing ductal differentiation by immunohistochemistry CEA: Carcinoembryonic antigen

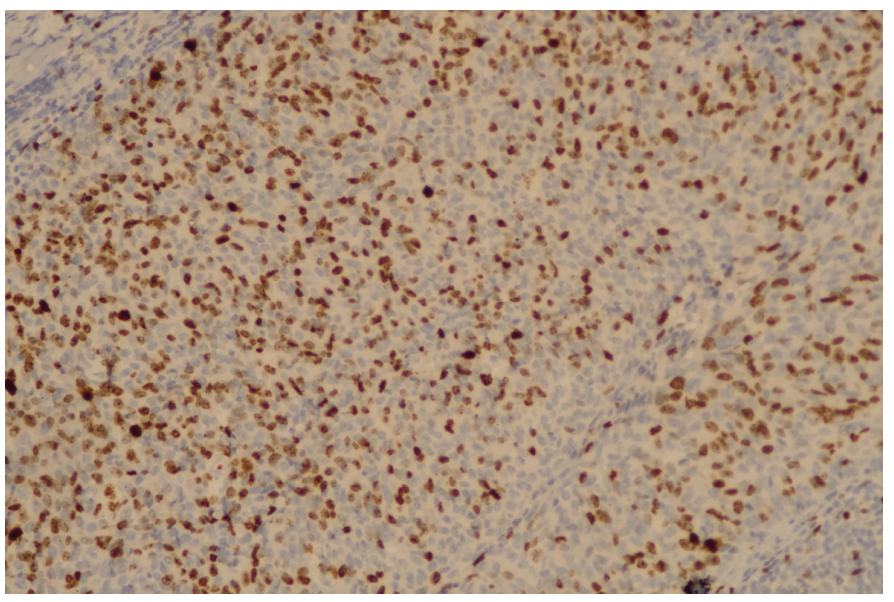

Figure 7. Ki-67 proliferation index
In a study by Robson et al. (14), the relationship between tumor size, prognosis, or lymph node involvement could not be demonstrated. However, involvement deeper than $7 \mathrm{~mm}$ and lymph node involvement were found to be associated with poor prognosis. High mitotic index and lymphovascular invasion have also been shown to be associated with poor prognosis (14). Our case shows high mitotic activity and the depth of the tumor is more than $7 \mathrm{~mm}$. There were no lymph node metastasis and distant organ metastasis during follow-up.

Benign skin appendix tumors, squamous cell carcinoma, basal cell carcinoma, malignant melanoma, and metastatic carcinomas should also be included in the differential diagnosis in cases of eccrine porocarcinoma. It can be distinguished from benign skin appendix tumors by the presence of invasive areas, cytological atypia, and pleomorphism. Differential diagnosis with squamous cell carcinoma can be made by the presence of ductal differentiation areas and in situ areas. Absence of peripheral palization and immunohistochemically BerEp4 negativity may be helpful in the differential diagnosis from basal cell carcinoma. The presence of negative staining with s100 immunohistochemically and positive staining with cytokeratin are helpful in the differential diagnosis of malignant melanoma.

\section{CONCLUSION}

Eccrine porocarcinoma is a rare malignant sweat gland tumor with a high risk of recurrence and metastasis. It is included in the differential diagnosis of several clinical entities, including benign skin appendix tumors, basal cell carcinoma, squamous cell carcinoma, and metastatic carcinomas. Despite being rare, eccrine porocarcinoma is the most common sweat gland tumor and should always be considered in able to determine the prognosis and the correct treatment of this disease.

\section{Ethics}

Informed Consent: Verbal consent was obtained from the patient.

Peer-review: Externally peer-reviewed.

\section{Authorship Contributions}

Surgical and Medical Practices: A.B.G., Ö.Y., E.M., Concept: A.B.G., Ö.Y., Design: A.B.G., Ö.Y., E.M., Data Collection or Processing: A.B.G., Ö.Y., E.M., Analysis or Interpretation: A.B.G., Ö.Y., Literature Search: A.B.G., Ö.Y., Writing: A.B.G., Ö.Y.

Conflict of Interest: No conflict of interest was declared by the authors. 
Financial Disclosure: The authors declared that this study received no financial support.

\section{REFERENCES}

1. Pinkus $\mathrm{H}$, Mehregan $\mathrm{AH}$. Epidermotropic eccrine carcinoma. A case combining features of eccrine poroma and Paget's dermatosis. Arch Dermatol 1963;88:597-606.

2. Nazemi A, Higgins $S$, Swift $R$, In $G$, Miller $K$, Wysong A. Eccrine Porocarcinoma: New Insights and a Systematic Review of the Literature. Dermatol Surg 2018;44:1247-61.

3. McGuire C, Fadel Z, Samargandi O, Williams J. Primary eccrine porocarcinoma of the thumb with multiple metastases: a case report and review of the literature. Case Reports Plast Surg Hand Surg 2019;6:88-91.

4. Torbeck R, Fazio J, Lee JB, Trufant J. Eccrine porocarcinoma presenting as a recurrent wart. Cutis 2019;103:166-8.

5. Ekmekci S, Lebe B. Eccrine Porocarcinoma of the Scalp. Turk Patoloji Derg 2013;156-9.

6. Devi NR, Valarmathi K, Lilly M, Satish S, Mishra N. Primary Axillary Porocarcinoma: A Rare Cutaneous Tumour. J Clin Diagn Res 2016;10:ED04-6.
7. Cardoso JC, Calonje E. Malignant sweat gland tumours: an update. Histopathology 2015;67:589-606.

8. Shen J, Pan X, Lu Y, Pan D, Ma Y, Zhan R. A case of eccrine porocarcinoma characterized by a progressive increase in the level of Ki-67 index: case report and review of literature. BMC Surg 2019;19:142.

9. Kitamura K, Kinehara M, Tamura N, Nakamura K. Hidroacanthoma simplex with invasive growth. Cutis 1983;32:83-4, 86-8.

10. Bardach $\mathrm{H}$. Hidroacanthoma simplex with in situ porocarcinoma. A case suggesting malignant transformation. J Cutan Pathol 1978;5:236-48.

11. Kazakov DV, Kutzner H, Spagnolo DV, Kempf W, Zelger B, Mukensnabl P, et al. Sebaceous differentiation in poroid neoplasms: report of 11 cases, including a case of metaplastic carcinoma associated with apocrine poroma (sarcomatoid apocrine porocarcinoma). Am J Dermatopathol 2008;30:21-6.

12. Wollina U, Castelli E, Rülke D. Immunohistochemistry of eccrine poroma and porocarcinoma--more than acrosyringeal tumors? Recent Results Cancer Res 1995; 139:303-16.

13. Gu LH, Ichiki Y, Kitajima Y. Aberrant expression of p16 and RB protein in eccrine porocarcinoma. J Cutan Pathol 2002;29:473-9.

14. Robson A, Greene J, Ansari N, Kim B, Seed PT, McKee PH, et al. Eccrine porocarcinoma (malignant eccrine poroma): a clinicopathologic study of 69 cases. Am J Surg Pathol 2001;25:710-20. 